\title{
Prevalence and incidence of peptic ulcer disease in a Danish County - a prospective cohort study
}

\author{
S J Rosenstock, T Jørgensen
}

The Glostrup

Population Studies,

Department of

Internal Medicine C,

Glostrup Hospital,

University of

Copenhagen, Denmark

S J Rosenstock

Department of

Surgery K, Bispebjerg

Hospital, Copenhagen,

University of

Copenhagen, Denmark

T Jørgensen

Correspondence to:

Dr S Rosenstock,

Department of Surgery K,

Bispebjerg Hospital,

Bispebjerg Bakke 23,

DK2400, Copenhagen,

University of Copenhagen,

Denmark.

Accepted for publication 7 October 1994

\begin{abstract}
Peptic ulcer prevalence and five year incidence were assessed in a sex and age stratified population sample of 3608 Danish subjects aged 30-60 years. Statements of peptic ulcer disease obtained from questionnaires were scrutinised by reviewing medical records. Life time ulcer prevalence (95\% confidence intervals) was $5.6(4 \cdot 9-6 \cdot 4)$ per cent. Male to female prevalence ratio was $2 \cdot 2: 1$, and duodenal to gastric ulcer prevalence ratio was $3 \cdot 8: 1$. Thirty two participants with no previous history of peptic ulceration developed an ulcer within the observation period resulting in a five year ulcer incidence of $11 \cdot 3$ $(7 \cdot 4-15 \cdot 2)$ per 1000 persons at risk with no demonstrable sex difference. The prevalence of duodenal ulcer has declined in Denmark whereas gastric ulcer prevalence in men has increased slightly. A decline in male duodenal ulcer incidence has probably contributed to the low male to female ulcer incidence ratio, implying that women today incur the same risk of developing an ulcer as men. If such trends
\end{abstract}

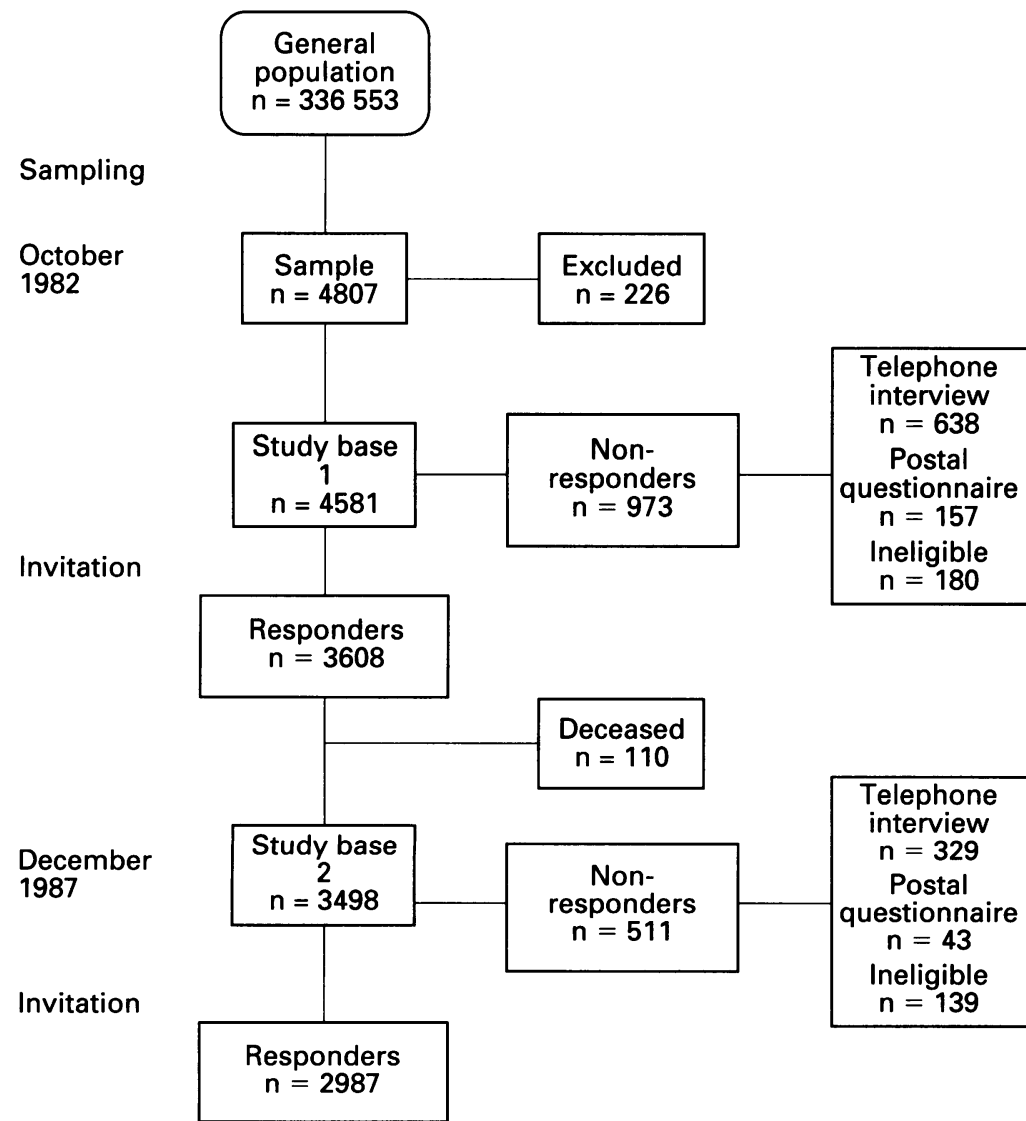

Sampling and response pattern among 4581 Danes invited to a population survey in October 1982. continue, they will bring about a new era in ulcer epidemiology characterised by equal incidence in men and women and an even distribution of lesions in the stomach and duodenum.

(Gut 1995; 36: 819-824)

Keywords: peptic ulcer, duodenal ulcer, gastric ulcer, epidemiology, prevalence, incidence.

Since the mid-twentieth century peptic ulcer mortality in Westernised countries has declined in young and middle aged subjects. Ulcer mortality in senior citizens has, none the less, remained essentially unchanged or even increased. ${ }^{1}$ Similar trends have been seen when other frequency estimates of ulcer occurrence such as hospitalisation, operation, and physician visit rates have been reviewed. ${ }^{2}$ Assessment of true peptic ulcer rates do, however, pose several methodological problems. ${ }^{3}$ Preferably prevalence and incidence rates should be based only on cases verified by endoscopy, roentgenograms or surgery. Gastric and duodenal ulcer rates should be reported separately and ulcer incidence calculated exclusively from first time verified lesions.

As ulcers are present intermittently, simply performing endoscopies on a representative sample of subjects does not ensure valid estimates of ulcer occurrence. Consequently, most previous studies have used hospitalisation rates and mortality as approximate measures of overall ulcer occurrence. Those findings are probably impaired by selection bias. Self reported ulcer occurrence likewise could be prone to bias. Provided that an unselected population is used, however, such an approach does have several advantages making it the most suitable means of determining the prevalence and incidence of peptic ulceration.

This study reports the lifetime prevalence and five year incidence of peptic ulcer disease in an unselected Danish population. Ulcer incidence was computed exclusively from ulcer episodes occurring among participants with no previous history of peptic ulceration at study entry. Furthermore, ulcers were classified according to location whenever possible.

\section{Methods}

SAMPLING AND INVITATION

In October 1982 a random sample of 4807 men and women, born in 1952, 1942, 1932, and 1922 (age 30, 40, 50, and 60 years) 
residing in the western part of Copenhagen County, was drawn from the Danish Civil Registration System. ${ }^{4}$ Total population of the sampling area was 336553 (Figure). All members of the sample were invited to a general health examination by a standard letter containing information about the project. Enclosed was a questionnaire concerning medical history and health and lifestyle practices to be completed in advance. The first examination took place between November 1982 and February 1984. All participants of Danish extraction were reinvited after five years to a re-examination conducted between December 1987 and November 1988.

On both occasions subjects who did not respond were reinvited by post. Those who refused to participate were contacted and interviewed by telephone. If they could not be reached by telephone a final letter asking them to contact the investigation leaders was sent. Finally, sample members from whom no information had been obtained were asked to complete a postal questionnaire. Examination outside working hours and free transportation were offered when necessary.

The project was approved by the Regional Research ethics committee of the Copenhagen County.

\section{RESPONSE PATTERNS}

Sample size was reduced to 4581 subjects because of the exclusion of 226 persons of foreign extraction (Figure).

The prevalence study-response rate was 78.8 per cent (3608/4581). Information was obtained from 81.5 per cent (793 of 973) of the non-responders by telephone interviews or postal questionnaires. Ineligible were those who had disappeared, had died between sampling and examination, or those who refused to participate.

The incidence study-one hundred and ten participants had died over the five year observation period. The remaining responders from the prevalence study $(n=3498)$ were reinvited regardless of previous ulcer diagnosis, and 85.4 per cent $(n=2987)$ attended the follow up examination (Figure). A total number of 2830 responders remained at risk of developing an ulcer as 157 of those attending the incidence study had reported an ulcer at study entry. Among non-responders in the incidence study $(n=511)$, we retrieved information from $72 \cdot 7$ per cent $(n=372)$ by telephone interviews or postal questionnaires. Four per cent (139 of 3498) of the eligible study population was lost to follow up.

\section{QUESTIONNAIRE}

To estimate lifetime ulcer prevalence in 1982, and five year incidence in the period 1982 to 1987 participants were asked to report if they, before the study entry or during the five year observation period, had an ulcer diagnosed. This line of procedure ensured that incidence rates were calculated only from first time diagnosed ulcers. In addition participants stated if they had a gastroscopy, a radiological examination of the upper gastrointestinal tract or an ulcer operation performed. Affirmative answers were substantiated by a thorough review of medical records. Questionnaires were scrutinised to correct for obvious errors and omissions.

\section{DIAGNOSTIC VERIFICATION}

Index cases were those who claimed that they had an ulcer verified by $x$ ray, endoscopy or operation. Statements of previous ulcer diagnosis were accepted in cases where medical records were inaccessible to substantiate diagnosis. These ulcers were categorised according to the location reported by the participant or as unclassified ulcer if participants were unaware of ulcer location. $x$ Rays or endoscopies were not repeated, but descriptions were reviewed. Consequently, the diagnostic subgroupings prevail on the judgement of the radiologist or endoscopist, subsequently validated by the authors.

\section{ULCER CLASSIFICATION}

Active ulcers were categorised as either duodeno-pyloric ulcers, gastric ulcers, or combined ulcers. Lesions were considered to be gastric ulcers when craters were seen in the corpus-fundus or antrum area excluding the pyloric canal. Craters located in the pyloric canal, or in the duodenum, were classified as duodeno-pyloric ulcers. The term combined ulcer was applied if lesions were seen both proximal and distal to the pyloric ring during the same examination. Scars or deformities were accepted as signs of former ulcer. Outcomes described as possible ulcer were interpreted as ulcers. Malignant ulcers $(n=2)$ were excluded from calculations.

\section{FALSE POSITIVE AND FALSE NEGATIVE} STATEMENTS

One fifth $(n=752)$ of those attending the prevalence study had undergone diagnostic procedures of the upper gastrointestinal tract before the study entry. Information was obtained in 56.2 per cent $(n=423)$ of these cases revealing 4.3 per cent false positive and $3 \cdot 1$ per cent false negative statements of ulcer occurrence. Of responders in the incidence study 6.9 per cent $(n=209)$ were examined within the observation period and 82.6 per cent $(n=170)$ of these results were accessible. There were 3.5 per cent false positive and 1.8 per cent false negative statements of ulcer occurrence. Most self reportations were thus consistent with diagnostic findings. Erroneous statements were identified and corrected according to the diagnosis stated in the diagnostic reports.

\section{SAMPLE VALIDITY}

The external sample validity was ensured by comparing the distribution of sex, age, occupation, and marital status in the sampling area 
TABLE I Lifetime ulcer prevalence (per cent) in 1982 according to sex, age, and response pattern ( $n=$ denominator)

\begin{tabular}{lcc}
\hline & $\begin{array}{l}\text { Responders } \\
\%(n)\end{array}$ & $\begin{array}{l}\text { Non-responders } \\
\%(n)\end{array}$ \\
\hline Males/age (y) & & \\
30 & $2 \cdot 4(454)$ & $1 \cdot 4(71)$ \\
40 & $4 \cdot 9(473)$ & $6 \cdot 6(76)$ \\
50 & $9 \cdot 7(465)$ & $9 \cdot 1(77)$ \\
60 & $13 \cdot 5(451)$ & $8 \cdot 4(107)$ \\
Crude rate & $7 \cdot 6(1843)$ & $7 \cdot 1(331)$ \\
$95 \%$ CI $\dagger$ & $(6 \cdot 4-8 \cdot 8)$ & $(4 \cdot 3-9 \cdot 9)$ \\
Adjusted rate & $7 \cdot 7$ & $6 \cdot 4$ \\
Females/age (y) & & \\
30 & $0 \cdot 7(457)$ & $0 \cdot 0(93)$ \\
40 & $2 \cdot 2(460)$ & $2 \cdot 0(104)$ \\
50 & $4 \cdot 4(450)$ & $8 \cdot 6(105)$ \\
60 & $7 \cdot 0(398)$ & $5 \cdot 7(159)$ \\
Crude rate & $3 \cdot 5(1765)$ & $4 \cdot 3(461)$ \\
$95 \%$ CI & $(2 \cdot 6-4 \cdot 4)$ & $(2 \cdot 4-6 \cdot 2)$ \\
Adjusted rate & $3 \cdot 6$ & $4 \cdot 1$ \\
\hline
\end{tabular}

$\star$ Crude rates were adjusted by direct standardisation. $\nmid 95 \%$ confidence intervals (CIs) for crude rates were generated from the binomial distribution.

with national statistics. There was a minor overrepresentation of unskilled workers and younger people ( $<50$ years) compared with Copenhagen County as a whole. Compared with the entire country, an under-representation of workers employed in agriculture, horticulture, and fishery, as well as fewer self employed people and unskilled workers were shown.

To test internal validity informations were provided by the only $x$ ray clinic serving the study area from 1976 to 1982 .

\section{STATISTICAL METHODS}

The SPSS statistical application for Windows and SYSTAT statistical application for the Macintosh were used. Cross tabulations were used for the comparison of sex, age, and response groups. Risk estimates generated from cross tabulations were expressed as relative risks. When stratification was applied a summary odds ratio $\left(\mathrm{OR}_{\mathrm{M}-\mathrm{H}}\right)$ was calculated as proposed by Mantel and Haenszel. ${ }^{5}$ Ninety five per cent confidence intervals for odds ratios and relative risks were computed by the method of Miettinen using the $\chi^{2}$ test value. ${ }^{6}$ Standard deviations obtained from the

TABLE II Lifetime ulcer prevalence (per cent) in 1982 according to ulcer site, sex, age

\begin{tabular}{|c|c|c|c|}
\hline & $\begin{array}{l}\text { Males } \\
\%(95 \% C I)^{\star}\end{array}$ & $\begin{array}{l}\text { Females } \\
\%(95 \% C I)^{\star}\end{array}$ & $\begin{array}{l}\text { M:F } \\
\text { ratio } \neq\end{array}$ \\
\hline \multicolumn{4}{|c|}{ Duodenal ulcers/age (y) } \\
\hline 30 & $1 \cdot 3(0 \cdot 3-2 \cdot 3)$ & $0.2(0.0-0.6)$ & $6 \cdot 5: 1$ \\
\hline 40 & $3 \cdot 0(1 \cdot 5-4 \cdot 5)$ & $1.5(0.4-2.6)$ & $2 \cdot 0: 1$ \\
\hline 50 & $4 \cdot 5(2 \cdot 6-6 \cdot 4)$ & $2 \cdot 7(1 \cdot 2-4 \cdot 2)$ & $1 \cdot 7: 1$ \\
\hline 60 & $8 \cdot 2(5 \cdot 7-10 \cdot 7)$ & $3 \cdot 3(1 \cdot 5-5 \cdot 1)$ & $2 \cdot 5: 1$ \\
\hline Crude rate $\nmid$ & $4 \cdot 3(3 \cdot 4-5 \cdot 2)$ & $1.9(1.3-2 \cdot 5)$ & $2 \cdot 3: 1$ \\
\hline \multicolumn{4}{|c|}{ Gastric ulcers/age (y) $\int$} \\
\hline 30 & $0.2(0.0-0.6)$ & 0 & - \\
\hline 40 & $0.6(0.0-1 \cdot 3)$ & $0.2(0.0-0.6)$ & $3 \cdot 0: 1$ \\
\hline 50 & $2.3(0.9-3 \cdot 7)$ & $0.9(0.0-1.8)$ & $2 \cdot 6: 1$ \\
\hline 60 & $2 \cdot 0(0 \cdot 7-3 \cdot 3)$ & $1 \cdot 3(0 \cdot 2-2 \cdot 4)$ & $1 \cdot 5: 1$ \\
\hline Crude rate† & $1 \cdot 2(0 \cdot 7-1 \cdot 7)$ & $0.6(0.2-1.0)$ & $2 \cdot 0: 1$ \\
\hline \multicolumn{4}{|c|}{ Unclassified ulcers/age (y) } \\
\hline 30 & $0.9(0.0-1 \cdot 8)$ & $0.4(0.0-1.0)$ & $2 \cdot 3: 1$ \\
\hline 40 & $1 \cdot 3(0 \cdot 3-2 \cdot 3)$ & $0.4(0.0-1.0)$ & $3 \cdot 3: 1$ \\
\hline 50 & $2 \cdot 8(1 \cdot 3-4 \cdot 3)$ & $0.9(0.0-1.8)$ & $3 \cdot 1: 1$ \\
\hline 60 & $3 \cdot 3(1 \cdot 7-5 \cdot 0)$ & $2 \cdot 5(1 \cdot 0-4 \cdot 0)$ & $1 \cdot 3: 1$ \\
\hline Crude rate $†$ & $2 \cdot 1(1 \cdot 4-2 \cdot 8)$ & $1.0(0.5-1.5)$ & $2 \cdot 1: 1$ \\
\hline
\end{tabular}

* $95 \%$ confidence intervals (CIs) were generated from the binomial distribution. †Adjusted rates were identical to crude rates. $¥$ Male to female prevalence ratio. $\$$ Two cases of combined ulcers were included in the gastric ulcer category. There were no cases of gastric ulcer reported among 30 year old women. binomial distribution were used to compute $95 \%$ confidence intervals for rates. ${ }^{7}$ The test for trend was used to detect any trends in proportions with age. ${ }^{7}$ Direct standardisation was performed to adjust for the confounding effects of differences in sex and age distributions of responders and non-responders using the sum of the populations participating as standard.

\section{Results}

LIFETIME ULCER PREVALENCE

The crude lifetime prevalence in responders was $5 \cdot 6(4 \cdot 9-6 \cdot 4)$ per cent. Table I shows sex and age specific ulcer prevalences. An age related increase in ulcer prevalence was shown in both sexes (test for trend, $\chi^{2}$ males $=43.9$, $\left.\chi_{\text {females }}^{2}=29 \cdot 2, \mathrm{df}=1, \mathrm{p}<0 \cdot 001\right)$. This trend was evident in all ulcer locations except for gastric ulcer prevalence in men (Table II). Men were significantly more likely to report an ulcer at study entry than women irrespective of ulcer location (males $><$ females $\mathrm{OR}_{\mathrm{M}-\mathrm{H}}$ test: duodeno-pyloric ulcer: $2.3(1.5-3 \cdot 3)$, gastric ulcer: $2 \cdot 2(1 \cdot 1-4 \cdot 5)$, unclassified ulcer: $2 \cdot 1$ $(1 \cdot 2-3 \cdot 6)$, resulting in an overall male to female prevalence ratio of $2 \cdot 2: 1$. The ulcer site specific male to female prevalence ratios showed a declining tendency with age in both sexes (Table II).

Overall duodeno-pyloric ulcer to gastric ulcer prevalence ratio was 3·8:1. Except for 60 year old men in which a disproportionately high duodeno-pyloric ulcer prevalence and low gastric ulcer prevalence was seen (Table II), sex specific duodeno-pyloric ulcer to gastric ulcer prevalence ratios attenuated with age.

Operative treatment of non-malignant ulcers had been undertaken in one per cent of participants before study entry.

\section{FIVE YEAR ULCER INCIDENCE}

Thirty two participants not suffering from peptic ulceration before entering the survey, reported an ulcer in the five year observation period. Five year ulcer incidence was 11.3 per 1000 persons at risk - that is, $12 \cdot 0$ for males and 10.6 for females. This difference is not significant (males $><$ females $\mathrm{OR}_{\mathrm{M}-\mathrm{H} \text { test }}$ : all ulcer locations: $1 \cdot 1(0 \cdot 6-2 \cdot 2)$ (Table III). The increase in incidence with age among men was insignificant (test for trend, $\chi_{\text {males }}^{2}=0.34$, $\mathrm{df}=1, \mathrm{p}>0.75$ ).

Table IV shows site specific five year ulcer incidence rates and corresponding male to female incidence ratios. No cases of combined ulcers were seen in the five year observation period. Sex differences in site specific ulcer incidence rates did not reach significance (males $><$ females: $\mathrm{OR}_{\mathrm{M}-\mathrm{H} \text { test }}$ : duodeno-pyloric ulcer: 2.6 (0.4-15.3), gastric ulcer: $1 \cdot 2$ $(0 \cdot 3-4 \cdot 6)$, unclassified ulcer: $1 \cdot 0(0 \cdot 1-14 \cdot 0)$. No trend was seen in male:female incidence ratios with increasing age.

Two participants $(0 \cdot 1$ per cent) had operative treatment of ulcers diagnosed within the observation period. 
TABLE III Five year ulcer incidence per 1000 persons at risk in 1987 according to sex, age, and response pattern ( $n=$ denominator $)$

\begin{tabular}{lll}
\hline & $\begin{array}{l}\text { Responders } \\
\text { incidence }(n)\end{array}$ & $\begin{array}{l}\text { Non-responders } \\
\text { incidence }(n)\end{array}$ \\
\hline Males/age (y) & & \\
35 & $5 \cdot 4(367)$ & $0 \cdot 0(36)$ \\
45 & $12 \cdot 7(393)$ & $27 \cdot 0(37)$ \\
55 & $11 \cdot 5(349)$ & $25 \cdot 0(40)$ \\
65 & $19 \cdot 3(311)$ & $22 \cdot 7(44)$ \\
Crude rate & $12 \cdot 0(1420)$ & $19 \cdot 1(157)$ \\
$95 \%$ CI & $(6 \cdot 3-17 \cdot 7)$ & $(0 \cdot 0-40 \cdot 5)$ \\
Adjusted rate & $12 \cdot 1$ & $18 \cdot 7$ \\
Females/age (y) & $10 \cdot 5(381)$ & $25 \cdot 0(40)$ \\
35 & $10 \cdot 6(378)$ & $0 \cdot 0(50)$ \\
45 & $14 \cdot 1(357)$ & $44 \cdot 4(45)$ \\
55 & $6 \cdot 8(294)$ & $71 \cdot 4(56)$ \\
65 & $10 \cdot 6(1410)$ & $36 \cdot 6(191)$ \\
Crude rate & $(5 \cdot 3-15 \cdot 9)$ & $(10 \cdot 0-63 \cdot 2)$ \\
$95 \%$ CI $\dagger$ & $10 \cdot 6$ & $33 \cdot 3$ \\
Adjusted rate* & & \\
\hline
\end{tabular}

${ }^{\star}$ Crude rates were adjusted by direct standardisation. $\lceil 95 \%$ confidence intervals (CIs) for crude rates were generated from the binomial distribution.

\section{ULCER RELAPSE}

Participants reporting a history of peptic ulcer in 1982 were more likely to experience an ulcer episode during the observation period than subjects not suffering from peptic ulceration at study entry (relative risk $10 \cdot 3(6 \cdot 5-16 \cdot 5)$ ).

Seventeen cases of ulcer relapse were verified within the observation period resulting in a five year ulcer recurrence rate of $7 \cdot 1$ per cent in male and 11.5 per cent in female ulcer patients respectively. In all 0.2 per cent ( 5 of 2987 ) of those attending the incidence study had surgery for recurrent ulcers. The location of relapse was not always identical to the original ulcer site. Thus, among 10 participants with a verified duodeno-pyloric ulcer at study entry, three relapses were categorised as gastric ulcers.

\section{NON-RESPONDERS}

\section{The prevalence study}

There was no significant difference in ulcer prevalence between non-responders and responders (responders $><$ non-responders $\mathrm{OR}_{\mathrm{M}-\mathrm{H} \text { test }}$ :males $1.3(0 \cdot 8-2 \cdot 0)$, females 0.9 $(0 \cdot 4-2 \cdot 0)$ ) (Table I). Among non-responders men were insignificantly more likely to report an ulcer than females $\mathrm{OR}_{\mathrm{M}-\mathrm{H} \text { test }} 1 \cdot 6(0 \cdot 9-3 \cdot 0)$ ).

Review of data provided by the only $x$ ray clinic serving the study area from 1976 to 1982 disclosed no significant overall difference between responders and non-responders in terms of $x$ ray investigations of the upper gastrointestinal tract performed. When stratified according to sex and age, however, more 60 year old female responders than non-responders had been examined (relative risk 2.9 $(1 \cdot 3-6 \cdot 5))$.

TABLE IV Five year ulcer incidence per 1000 persons at risk and male to female incidence ratio according to ulcer location

\begin{tabular}{llll}
\hline & $\begin{array}{l}\text { Male incidence } \\
(95 \% C I)^{\star}\end{array}$ & $\begin{array}{l}\text { Female incidence } \\
(95 \% C I)^{\star}\end{array}$ & $\begin{array}{l}\text { M:F } \\
\text { ratio }\end{array}$ \\
\hline Duodenal and pyloric ulcers & $6 \cdot 3(2 \cdot 2-10 \cdot 4)$ & $3 \cdot 5(0 \cdot 4-6 \cdot 6)$ & $1 \cdot 8: 1$ \\
Gastric ulcer & $3 \cdot 5(0.4-6 \cdot 6)$ & $2 \cdot 8(0 \cdot 1-5 \cdot 6)$ & $1 \cdot 3 \cdot 1$ \\
Unclassified ulcers & $2 \cdot 1(0 \cdot 0-4 \cdot 5)$ & $4 \cdot 3(0 \cdot 9-7 \cdot 7)$ & $0 \cdot 5: 1$ \\
\hline
\end{tabular}

$\star 95 \%$ confidence intervals (CIs) were generated from the binomial distribution. tMale to female five year incidence ratio.
The incidence study

Significantly more female non-responders than responders reported an ulcer within the observation period, however, this difference was insignificant among men (responders $><$ non-responders $\mathrm{OR}_{\mathrm{M}-\mathrm{H} \text { test }}$ :males 0.7 $(0 \cdot 2-2 \cdot 2)$, females $0.3(0 \cdot 1-0 \cdot 7)$ ) (Table III). Sample members who had attended the prevalence study but failed to attend the incidence study had significantly higher ulcer prevalences in 1982 than those sample members participating in both parts of the study (relative risk 1.5 $(1 \cdot 1-2 \cdot 0))$.

\section{Discussion}

Identifying appropriate study populations and measurement of outcome have often hampered ulcer epidemiological studies. Unbiased estimates of ulcer occurrence are only achieved if an unselected population is examined. Hospital based surveys could be prone to selection bias. ${ }^{8}$ Moreover hospitalised ulcer patients are more likely to be women, have gastric ulcers $^{19}$ or suffer from ulcer complications. The decline in hospitalisation rates of uncomplicated peptic ulcer seen within the past 40-50 years ${ }^{2}{ }^{10-12}$ may reflect the impact of histamine 2 blocking agents or a shift towards outpatient treatment of uncomplicated ulcers rather than a true decline in ulcer occurrence. Ulcer mortality is negligible compared with overall ulcer occurrence. ${ }^{1314}$ As haemorrhage or perforation often precede ulcer deaths, ${ }^{15}$ death rates are strongly influenced by changes in the ability to treat complications. Ulcer prevalence as found at necropsy varies from 4 to 20 per cent. ${ }^{16}$ Necropsy studies do offer an opportunity to assess the frequency of silent ulcers but the risk of missing an ulcer diagnosis, especially if death has not been preceded by ulcer symptoms, is rather large. It should also be kept in mind that such study populations are highly selected. Anti-ulcer drugs are often prescribed on dubious indications and figures based on treatment do not permit a distinction between ulcer sites, or between ulcer relapses and incident ulcers.

This study reports the lifetime prevalence and five year incidence of verified ulcers in an unselected population based on self reported ulcer occurrence. Overall ulcer prevalences among responders and non-responders were identical and information on the number of $x$ rays of the upper gastrointestinal tract performed between 1976 and 1982 provided by the $x$ ray clinic serving the area showed no significant differences between responders and non-responders except for those aged 60 years. Five year ulcer incidence and ulcer prevalence at study entry on the other hand were significantly higher in those who failed to attend the incidence study than in those participating in both studies. This might indicate that nonresponders in the incidence study represent a subgroup more likely to suffer from peptic ulcer disease.

The intermittent nature of peptic ulcer disease implies that a single normal endoscopy cannot rule out ulcer disease. It could 
TABLE V Lifetime ulcer prevalence (\%) in comparable studies

\begin{tabular}{|c|c|c|c|c|c|c|c|c|}
\hline \multirow[b]{2}{*}{ Author } & \multirow{2}{*}{$\begin{array}{l}\text { Year } \\
\text { of } \\
\text { survey }\end{array}$} & \multirow[b]{2}{*}{$\begin{array}{l}\text { Age } \\
\text { (y) }\end{array}$} & \multirow[b]{2}{*}{$\begin{array}{l}\text { Sample } \\
\text { size }\end{array}$} & \multicolumn{2}{|l|}{ Women } & \multicolumn{2}{|l|}{ Men } & \multirow[b]{2}{*}{$\begin{array}{l}\text { M:F } \\
\text { ratio }^{\star}\end{array}$} \\
\hline & & & & $\begin{array}{l}\text { Duodenal } \\
\text { ulcer }\end{array}$ & $\begin{array}{l}\text { Gastric } \\
\text { ulcer }\end{array}$ & $\begin{array}{l}\text { Duodenal } \\
\text { ulcer }\end{array}$ & $\begin{array}{l}\text { Gastric } \\
\text { ulcer }\end{array}$ & \\
\hline Hansen (DK)†‡ & 1946 & $>15$ & 32037 & $1 \cdot 6$ & $4 \cdot 0$ & $4 \cdot 6$ & $2 \cdot 3$ & $1 \cdot 2: 1$ \\
\hline Hagerup (DK) & 1965 & 50 & 802 & $2 \cdot 7$ & $0 \cdot 3$ & $8 \cdot 5$ & 0.5 & $3 \cdot 2: 1$ \\
\hline Banke (DK) $\ddagger$ & 1967 & $>15$ & 1831 & $3 \cdot 5$ & 0.6 & $7 \cdot 3$ & 0.5 & $1.9: 1$ \\
\hline Kurata (US) & 1976 & $>24$ & 34198 & \multicolumn{2}{|c|}{$11 \cdot 0$} & \multicolumn{2}{|c|}{$13 \cdot 5$} & $1 \cdot 2: 1$ \\
\hline Khuroo (Ind) & 1985 & $>15$ & 2763 & $7 \cdot 2$ & $0 \cdot 2$ & $14 \cdot 0$ & $1 \cdot 0$ & $2 \cdot 0: 1$ \\
\hline Bernersen (N) & 1987 & $20-69$ & 2027 & $1 \cdot 4$ & $1 \cdot 1$ & $4 \cdot 4$ & $1 \cdot 4$ & $2 \cdot 3: 1$ \\
\hline Rosenstock (DK) & 1982 & $30-60$ & 3608 & 1.9 & 0.5 & $4 \cdot 2$ & $1 \cdot 1$ & $2 \cdot 2: 1$ \\
\hline
\end{tabular}

* Male to female prevalence ratio for all ulcer locations. †Necropsy study. $¥$ Rates are point prevalences.

$\S$ Lifetime prevalence: females $=11 \cdot 0 \%$, males $=13 \cdot 5 \%$, duodenal and gastric ulcers were grouped together.

nevertheless be argued that abstaining from endoscopying all participants leaves the possibility that we have missed part of the ulcers. Diagnostic procedures and hospital admissions are free of charge in Denmark. Even in Westernised countries, however, 25 per cent of dyspeptic patients do not seek medical advice ${ }^{17}$ and endoscopic findings in persons without dyspepsia suggest that one quarter of all ulcers are asymptomatic. ${ }^{18-20}$ As a result we definitely underestimate true rates.

Inaccessibility of medical records made it impossible to substantiate part of the statements regarding ulcer occurrence. We decided to include such statements after finding that self reports were in accordance with diagnostic outcomes in 93 to 95 per cent of the cases. It is inconceivable that the ulcer site distribution of unclassified ulcers should differ significantly from that of verified ulcers.

Erroneous reports were found in 1.8 to $4 \cdot 3$ per cent of the cases. As the number of false positive statements exceeded that of false negative statements, misclassifications were differential. Hence, to provide the most accurate estimates of ulcer prevalence and incidence, corrections were made according to the diagnosis stated in diagnostic reports in those cases for which medical records were accessible.

Table $\mathrm{V}$ shows ulcer prevalences reported in comparable studies. ${ }^{19-24}$ The prevalence of duodenal ulcers has declined in Denmark in both sexes since the mid-sixties, ${ }^{23}{ }^{24}$ whereas the prevalence of gastric ulcers is increasing in men. The prevalence of gastric ulcers is in general higher in postmortem surveys than in studies using a living population. The magnitude of the female gastric ulcer prevalence reported in the necropsy study by Hansen ${ }^{23}$ suggests, however, that a considerable decline in gastric ulcer prevalence in women took place between 1946 and the mid-sixties. The prevalence of self reported ulcers reported by Bernersen in northern Norway ${ }^{19}$ is consistent with our findings except for gastric ulcer, which has previously been established as more frequent in the northern parts of Europe..$^{25} 26$ The lifetime prevalences reported by Khuroo ${ }^{20}$ in India were much higher than those found in this report because of an appreciable preponderance of duodenal ulcers. Peptic ulcer disease is more frequent in developing countries and is recognised by an appreciable outnumbering of gastric ulcers by duodenal ulcers and high male to female ratios. Studies by Goenka ${ }^{27}$ show that ulcer disease in India is now approaching Western patterns as they were four to five decades ago. Kurata 22 estimated the lifetime prevalence of unclassified ulcers in a population of Seventh Day Adventists using self reported ulcer occurrence. Ulcer prevalence in both sexes was considerably higher than in this study, which is surprising in view of the low rate of tobacco smoking reported in the study population. Differences in age composition of study populations and hereditary factors may explain these dissimilarities.

The small number of ulcers reported during the observation period in this study justifies only limited inference on ulcer incidence. Table VI shows the annual ulcer incidence per 1000 persons at risk in similar studies. ${ }^{128-36}$ Comparing our findings to previous Danish studies $^{28-30}$ suggests that the incidence of duodeno-pyloric ulcer seems to be unchanged in women but decreasing in men while the incidence of gastric ulcer could be increasing in both sexes (Table VI). Compared with international studies our results are in accordance with most recent reports. ${ }^{131-36}$ Male to female ulcer incidence ratio has attenuated steadily since the beginning of the 1950 s and this study does in fact report the lowest male to female

TABLE VI Annual ulcer incidence per 1000 persons at risk in comparable studies

\begin{tabular}{|c|c|c|c|c|c|c|c|c|}
\hline \multirow[b]{2}{*}{ Author } & \multirow{2}{*}{$\begin{array}{l}\text { Year } \\
\text { of } \\
\text { survey }\end{array}$} & \multirow[b]{2}{*}{$\begin{array}{l}\text { Age } \\
(y)\end{array}$} & \multirow{2}{*}{$\begin{array}{l}\text { Number } \\
\text { of } \\
\text { cases }\end{array}$} & \multicolumn{2}{|l|}{ Females } & \multicolumn{2}{|l|}{ Males } & \multirow[b]{2}{*}{$\begin{array}{l}\text { M:F } \\
\text { ratio }^{\star}\end{array}$} \\
\hline & & & & $\begin{array}{l}\text { Duodenal } \\
\text { ulcer }\end{array}$ & $\begin{array}{l}\text { Gastric } \\
\text { ulcer }\end{array}$ & $\begin{array}{l}\text { Duodenal } \\
\text { ulcer }\end{array}$ & $\begin{array}{l}\text { Gastric } \\
\text { ulcer }\end{array}$ & \\
\hline Alsted (DK) & 1940 & $>15$ & 629 & $0 \cdot 2$ & 0.1 & 0.6 & $0 \cdot 1$ & $2 \cdot 4: 1$ \\
\hline Sponheim (N) & $1951-52$ & $>10$ & 811 & $1 \cdot 6$ & 0.8 & $6 \cdot 7$ & 1.5 & $3 \cdot 3: 1$ \\
\hline Pulvertaft (UK) & $1952-57$ & $>15$ & 1132 & 0.6 & 0.3 & $2 \cdot 2$ & 0.5 & $2 \cdot 9: 1$ \\
\hline Bonnevie (DK) & $1963-68$ & $>15$ & 1905 & $0 \cdot 8$ & $0 \cdot 3$ & 1.8 & $0 \cdot 3$ & $1.9: 1$ \\
\hline Kurata (US) $\dagger$ & $1977-80$ & $>15$ & 349 & 0.4 & $0 \cdot 2$ & 0.8 & 0.2 & $1 \cdot 8: 1$ \\
\hline Johnsen (N)t & $1979-80$ & $20-54$ & 328 & 0.9 & 0.9 & $2 \cdot 0$ & 1.5 & $2 \cdot 0: 1$ \\
\hline Østensen (N) & $1980-83$ & $16-93$ & 503 & $0 \cdot 8$ & 0.9 & 1.5 & $1 \cdot 4$ & $1 \cdot 7: 1$ \\
\hline Kiær (FI) $\ddagger$ & $1981-83$ & $>15$ & 319 & 1.5 & $0 \cdot 7$ & $3 \cdot 1$ & $1 \cdot 3$ & $1 \cdot 9: 1$ \\
\hline Schöön (Swe) & 1985 & $>15$ & 1402 & 1.6 & $1 \cdot 2$ & 2.9 & 1.0 & $1 \cdot 4: 1$ \\
\hline Rosenstock (DK) & 1983-87 & $30-65$ & 32 & $0 \cdot 7$ & 0.5 & $1 \cdot 3$ & 0.7 & $1 \cdot 1: 1$ \\
\hline
\end{tabular}

$\star$ Male to female annual incidence ratio for all ulcer locations. †Counts are number of person years of observation. $\ddagger$ Faroe Islands. §Five year incidence was divided by number of observation years to obtain the annual ulcer incidence. 
incidence ratio ever. Whereas the sex specific incidence rates of gastric ulcer have approached equality in several previous studies, ${ }^{129} 32-34$ the incidence of duodenal ulcers in general has been higher in men than in women resulting in a male predominance in overall ulcer incidence. The low male to female incidence ratio reported in this study may emerge from a considerable decline in male duodenal ulcer incidence and a less pronounced increase in male and female gastric ulcer incidence. Our findings may thus herald a new era in peptic ulcer epidemiology characterised by equal affliction of the sexes as well as a more even distribution of ulcers in the stomach and duodenum.

Further follow up will allow us to examine whether these trends continue.

In conclusion, Danish peptic ulcer prevalence rates are comparable with other Scandinavian countries but in general are lower than reported in both the United States and in developing countries. Duodenal ulcer prevalence has declined in Denmark since the late 1960s whereas the prevalence of gastric ulcer has increased slightly in men. These trends are in accordance with our results on ulcer incidence. The sex specific incidence rates shown in this survey imply that women today incur the same risk as men of acquiring peptic ulcer disease. Furthermore, the changes seen in site specific incidence rates may point towards an even distribution of anatomical ulcer sites in the future.

This survey was supported by grants from the Danish Hospital Foundation for Medical Research, Region of Copenhagen, the Faroe Islands and Greenland (96/92), The Foundation of 1870 , Ove Villiam Buhl Olesen and spouse Edith Buhl Olesens Foundation (3555-11), and Jacob Madsens and spouse Olga Foundans Foundation (2211). Madsens Foundation (2211). The authors wish to express their gratitude to chief physician, MD, DM Sci Olaf Bonnevie, University of Copenhagen, Department of Gastroenterology, Frederiksberg Hospital, and Professor of Medicine, DM Sci
Povl Riis, University of Copenhagen Medical Department C, Povl Riis, University of Copenhagen Medical Department C, Herlev University
and critical review.

1 Kurata JH, Honda GD, Frankl $\mathrm{H}$. The incidence of duodenal and gastric ulcers in a large health maintenance organization. Am f of Publ Health 1985; 75: 625-9.

2 Bloom BS. Cross-national changes in the effects of peptic ulcer disease. Ann Intern Med 1991; 114: 558-62.

3 Kurata JH. Ulcer epidemiology: an overview and proposed research framework. Gastroenterology 1989; 96: 569-80. 4 Hougaard Jensen K, Jørgensen T. Incidence of gallstones in a Danish population. Gastroenterology 1991; 100: 790-4. 5 Mantel N, Haenszel W. Statistical aspects of the analysis of data from retrospective studies of disease. $\mathcal{F}$ Natl Cancer Inst 1959; 22: 719-48.

6 Miettinen OS. Estimability and estimation in case-referent studies. Am f Epidemiol 1976; 103: 226-35.

7 Armitage PA, Berry G. Statistical methods in medical research. 2nd ed. Oxford: Blackwell Scientific, 1987.

8 Roberts RS, Spitzer WO, Delmore T, Sackett DL. An empirical demonstration of Berkson's bias. 7 Chron Dis 1978; 32: 119-28.
9 Brazer SR, Tyor MP, Pancotto FS, Nicholas JN, Wildermann NM, Harrell FE, et al. Studies of gastric ulcer by community-based gastroenterologists. $\mathrm{Am} \mathcal{F}$ of Gastroenterol 1990; 85: 824-8.

10 Bloom BS, Gessner U. Mortality, hospitalization and work loss due to peptic ulcer and gastritis/duodenitis in the Federal Republic of Germany. Intl f of Technol Assess Health Care 1989; 5: 215-26.

11 Fineberg HV, Pearlman LA. Surgical treatment of peptic ulcer in the United States. Trends before and after the introduction of cimetidine. Lancet 1981; i: 1305-7.

12 Coggon D, Lambert P, Langman MJS. 20 years of hospital admissions for peptic ulcer in England and Wales. Lancet 1991; i: 1302-3.

13 Bonnevie O. Survival in peptic ulcer. Gastroenterology 1978; 75: $1055-60$

14 La Vecchia C, Lucchini F, Negri E, Reggi V, Levi F. The impact of therapeutic improvements in reducing peptic ulcer mortality in Europe. Int $\mathcal{f}$ Epidemiol 1993; 22: 96-106.

15 Henry DA, Johnston A, Dobson A, Duggan J. Fatal peptic ulcer complications and the use of non-steroidal antiinflammatory drugs, aspirin, and corticosteroids. $B M \mathcal{F}$ 1987; 295: 1227-9.

6 Langman MJS. The epidemiology of chronic digestive diseases. 1st ed. London: Edward Arnold, 1979: 9-39.

17 Jones R, Lydeard S. Prevalence of symptoms of dyspepsia in the community. BMF 1989; 298: 30-2.

18 Johnsen R, Bernersen B, Straume B, Førde OH, Bostad L, Burhol PG. Prevalences of endoscopic and histological findings in subjects with and without dyspepsia. $B M F$ 1991; 302: 749-52.

19 Bernersen B, Johnsen R, Straume B, Burhol PG, Jenssen TG, Stakkevold PA. Towards a true prevalence of peptic ulcer: The Sørreisa gastrointestinal disorder study. Gut 1990; 31: 989-92.

20 Khuroo MS, Mahajan R, Zargar SA, Javid G, Munshi S. Prevalance of peptic ulcer in India: an endoscopic and epidemiological study in urban Kashmir. Gut 1989; 30: 930-4.

21 Banke L. Ulkussygdommens Epidemiologi (Thesis). Copenhagen: F A D L s Forlag, 1975: 142-60.

22 Kurata JH, Nogawa AN, Abbey DE, Petersen F. A prospective study of risk for peptic ulcer disease in seventh-day adventists. Gastroenterology 1992; 102: 902-9.

23 Hansen JL. Andringer $i$ Ulkussygdommens fremtraden II (Thesis). Copenhagen: Ejnar Munksgaards Forlag, 1950.

24 Hagerup L, Geismar P, Rahbek I. Ulcer symptoms in population of 50 -year olds from the Glostrup investigation 1964-65. Ugesk Laeger 1971; 133: 1022-4.

25 Poppe E. Localization of peptic ulcer in a series of cases from Troms and Tromsø hospital, Norway. Tidskr Nor Laegeforen 1945; 30: 1063-5.

26 Tilvis RS, Vuoristo M, Varis K. Changing profile of peptic ulcer disease in hospital patients during 1969-84 in Finland. Scand $\mathcal{f}$ Gastroenterol 1987; 22: 1138-44.

27 Goenka MK, Kochar R, Ghosh P, Mehta SK. Changing pattern of peptic ulcer in India. An endoscopic study of pattern of peptic ulcer in India. An endoscopic study of 575-9.

28 Bonnevie O. The incidence of duodenal ulcer in Copenhagen County. Scand $\mathcal{f}$ Gastroenterol 1975; 10: 385-93.

29 Bonnevie O. The incidence of gastric ulcer in Copenhagen County. Scand F Gastroenterol 1975; 10: 231-9.

30 Alsted G. The incidence of peptic ulcer in Denmark (Thesis). Copenhagen: Danish Sci Press, 1950; 73-86.

31 Østensen H, Gudmundsen TE, Bolz KD, Burhol PG, Bonnevie O. The incidence of gastric and duodenal ulcer in north Norway. Scand f Gastroenterol 1985; 20: 189-92.

32 Johnsen R, Straume B, Førde OH, Burhol PG. Changing incidence of peptic ulcer - facts or artfacts? A cohort study incidence of peptic ulcer - facts or artfacts? A cohort study from $T$ T.

33 Pulvertaft CN. Peptic ulcer in town and country. Br fof Soc Med 1959; 13: 131-8.

34 Schöön I-M, Mellström D, Odén A, Ytterberg B-O. Incidence of peptic ulcer disease in Gothenburg, 1985. $B M \mathcal{1 9 8 9 ;} 299$ : 1131-4.

35 Kiær T, Roin J, Djurhuus S, Dahl Niclassen S, Bonnevie O. Epidemiological aspects of peptic ulcer disease on the Faroe Islands. An interim report. Scand 7 Gastroenterol 1985; 20: 1157-62.

36 Sponheim $\mathrm{N}$. The prevalence and incidence of peptic ulcer in a population. Nord Med 1960; 31: 377-408. 